\title{
Physiology of Neuroparasitism in Insects
}

\author{
N. Vijayaakshayakumar*, P. Yasodha and C. G. L. Justin \\ Department of Plant Protection, Anbil Dharmalingam Agricultural College \& Research \\ Institute, TNAU, Tiruchirappalli, TamilNadu, India \\ *Corresponding author
}

\begin{tabular}{l} 
K e y w o r d s \\
Neuroparasitology, \\
Neuroparasitism in \\
Insects \\
\hline Article Info \\
$\begin{array}{l}\text { Accepted: } \\
\text { 08 June } 2020 \\
\text { Available Online: } \\
\text { 10 July } 2020\end{array}$
\end{tabular}

A B S T R A C T

Parasites have evolved to manipulate the behavior of the host species, in which they dwell for their food and living. Since, most of the invertebrates comes under class Insecta, the chance of parasitization is always higher. In most cases, the manipulation occurs by influencing the nervous system of insects. The upcoming biological study, dealing with the manipulation of nervous system of insects by the parasites is neuroparasitology. From microscopic viruses to macroscopic worms, heterogeneity of parasites have evolved to become parasites (uniquely, parasitic wasps). It is striking that the manipulation spotted doesn't require direct entry into the brain and can occur even when the parasite is present external to the body or even at a distance from the host. The spatial view of manipulation would provide an integrated approach to investigate such interactions. Incorporation of different approaches from basic natural history to improved imaging techniques, omics and experiments will come up with new aspects in neuroparasitology. It is also recommended that for researchers interested in impending mechanism of insect behaviors, studies of parasites that have evolved to manipulate such behavior is of an important value in future to ascertain the host parasite interaction.

\section{Introduction}

Parasites are living organisms which depends on other organism, the host, for its survival. Due to its high reproductive potential, capacity to flight, and reduced size of insects, they are the dominant species in this planet, and have the chance to interact with the parasitic organisms than other species (Moore, 2002). Due to evolution, some parasite has gained the ability to disrupt the normal biochemical mechanisms of other organisms, that assists the parasites in its survival and transmission (Godfray and Godfray, 1994).

Some insects have evolved to gain assist and manipulate the behavior of the other insects of same class (Askew, 1971). Changes in the behavior of host organism by the parasites, may be due to the direct effects on the central nervous system and associated muscular 
system or indirectly manipulating the immune system and host's metabolism (Hughes and Libersat, 2018).

Host behavior is an extended phenotype of the parasite (Dawkins, 1982).Parasite-influenced changes in the host phenotypes were mostly adaptable for the parasitic species (Poulin, 1998), in case of confirming the suitable location for optimal release of parasites and its progenies (Maitland, 1994), the survival was increased by providing protection (Brodeur and McNeil, 1989) and also the behavior was altered, that they were likely eaten by other predatory insects, by acting as an intermediate host (Curtis, 1987). The amount of manipulation diversified from a slight variation in the pre-existing behavior (Rogers and Bates, 2007) to an entirely unique behavior that are never seen in unparasitized hosts (Eberhard, 2000). Edwards and Weaver (2000) noted that "parasitoid wasps have evolved a better 'understanding' of the subtleties and regulation of the endocrine systems of their insect hosts than is at present understood by insect physiologists".

Neuroparasitology is the budding branch of biology which deals with the study of parasites which are capable of controlling/influencing the nervous system of the host and its functions (Adamo and Webster, 2013). Many organisms, including viruses, bacteria, fungi, apicomplexans, diverse worms, and even other insects, have evolved to control the insect brain, because it is totally free from the host's immune systems (Galea et al., 2007) or it provides direct access to the insects to induce the manipulation (Webster, 2007).

By unveiling the mechanisms, by which the parasites induce behavioral changes, we can obtain new vision in the biology and to discover new genes, metabolites, proteins and developmental pathway that underlie the behavior manipulation. More precisely, such investigations provide new ideas into the mechanism of parasites spread and the mechanism by which the parasitic insects have evolved into neural manipulators, encountering the existing nervous system in the host (Hughes and Libersat, 2018).

\section{Different mechanisms of host behavior manipulation}

Regardless of numerous examples of hostparasite interaction, there are only few experimental examples which suggest the behavior manipulation of host by the parasite. This alteration in the host's behavior, has seems to benefit the parasite and not the host (Hughes and Libersat, 2018).

The different mechanism by which the host behavior is manipulated was grouped as

Neurological command from an extent

Approaching brain and influencing through ovipositor

Commanding brain while binding with the host

Influencing the host behavior during departure

Ruling the brain by residing in body cavity

Relocating to the brain to manipulate behavior

\section{Neurological command from an extent}

A typical example of mutualism is the attraction of ants to honey dew secretions of homopteran bugs and in exchange provide protection from the predators. Alike this, ants protect the Lycaeind caterpillars from predators and they were rewarded with sugar rich secretions from the caterpillar (Pierce et al., 2002). Ants have a dorsal nectary organ, on the seventh abdominal segment, which releases a sugar rich substance for the 
attendant ants. In the eighth segment, they have tentacle organs, which releases a volatile compound that resembles the alarm pheromone of the ants, and keep them aggressive around the caterpillar. In addition to these, the caterpillar produce surface chemicals, which is non-volatile, spread over the cuticle, suppress the ant aggression by mimicking the brood pheromone of ants and treat them as their own brood species (Akino et al., 1999).

A research study conducted by Hojo et al., (2015) focused on ants (Pristomyrmex punctatus) which tend the caterpillar (Narathura japonica). Ants provide protection to the caterpillar, and in change the ants were rewarded with the sugary secretions from the dorsal nectary organ. The secretions from the caterpillar made the attendant ants, more aggressive and less possible to move away from the caterpillar, which protects the host from other predators. This change in the behavior was due to the changes in dopamine level, as reduced level of dopamine was observed in the ants treated with the secretions of caterpillar. The ants continued to protect the caterpillar even when the sugary rewards were stopped. From here, mutualism was changed into parasitism. So, the caterpillar manipulated its host ants to move less likely away from them, and gain protection from the predators and parasitoids.

\section{Approaching brain and influencing through ovipositor}

Solitary wasps provoke paralysis in their hosts by stinging with their ovipositor. This immobility in host is due to the entry of venom into the nervous system of the host. The parasitoid jewel wasp (Ampulex compressa) uses cockroaches (Periplaneta americana) as a host for its progenies (Piek et al., 1989). The wasp generally stings the host twice, first in the thorax (prothoracic ganglion) which induces short-term paralysis in forelegs for a period of 1-3 minutes. For this transient paralysis, the wasp uses the approach of venom-induced synaptic block through chloride channel activation, and the venom contains high level of inhibitory neurotransmitters GABA, $\beta$-alanine and taurine compounds (Moore et al., 2006). This facilitates the second sting into the head, through neck membrane, which induces a long-term complete paralysis of the host.

A long-lasting immobility in cockroach was achieved by the wasp, by injecting the venom directly into supra-oesophageal ganglion (brain) and the sub-oesophageal ganglion. Since the insect brain is protected by the perineurium ("blood-brain barrier"), the brain cells are protected with restriction to entry of different compounds (Chapman, 2013). It is now visible that, the ovipositor of the wasp was developed exclusively to identify and target the brain cells thereby avoiding all other cells in the head region. This was achieved due to the presence of welldeveloped mechanoreceptors (campaniform sensilla and dome-shaped sensilla) in the ovipositor (Gal et al., 2014). Following the stung of wasp, cockroach performs continuous grooming for about 30 minutes. This immoderate grooming has been noted only after the sting on head and cannot be attributed to stress or to contamination of the body surface or to systemic or peripheral effects. This indicated that the venom was influencing the nervous system for grooming, by stimulating dopamine receptors in the cockroach (Weisel-Eichler et al., 1999).

In addition to this, the stung cockroach showed a reduced responsiveness to mechanical and sensitive stimuli that generally induce an escape response in an alert cockroach.

After stinging and paralyzing the host, the wasp uses its strong mandibles, to breaks off the cockroach's antennae and to drink 
hemolymph from the cut end. Notably, the cockroach doesn't show any defensive behavior in response to this stimulus. Such defensive behaviors to pain were termed as nocifensive. The unresponsiveness of the cockroach to stimuli allows the wasp to handle the cockroach further, lead it to burrow, and lay an egg on the cockroach's cuticle (Hughes and Libersat, 2018).

This prolonged behavioral change may be due to the results of venom-mediated changes in the neurochemistry of the brain. The venom compounds bind with the cerebral ganglia proteins of synapsis and presumably inhibit the pre- and post-synaptic conduction in the brain (Kaiser et al., 2019). This precise positioning of the venom and eggs in the brain of the host by parasite, has increased the fitness of the parasite, by preventing the encounter with specialized cells, called macrophages (Askew, 1971).

\section{Commanding brain while binding with the host}

Some parasitic wasps which are ectoparasites, lays its eggs on the host body surface. The emerging grubs, bore the cuticle and obtain the haemolymph. At the completion of their parasitic stage, they manipulate the behavior of the host by remaining on the body. These wasps are koinobiont ectoparasitoids which influence the web spinning pattern of the host spiders (Kloss et al., 2016). Since spiders are the natural predators, these wasps have evolved to attack and kill the predatory spiders, hence can be termed as predatory parasitoids.

The female ichneumonid wasp, Hymenoepimecis sp. attacks the spider Plesiometa argyra at the center of its orb web. The wasp stings the spider's mouth leading to temporary paralysis which helps the wasp to lay an egg on the spider's abdomen.
Eventually, the spider returns to its usual doing. Till the next fortnight, it builds normal orb webs to capture prey, the wasp's egg hatches and the grub feeds by sucking the spider's haemolymph. A day before pupation, the grub releases an unidentified substance, which influence the spider to produce a distinctive "cocoon web", different from the normal orb web. This cocoon web provides durable support to the wasp larva to hang down and thus to prevent the hyperparasitism (Eberhard, 2000).

Larva of ichneumonid wasp Zatypotaper contatoria, performed species-specific manipulation of theridiid spiders, Neottiurabi maculata and Theridion varians. Shortly before the pupation, the larva induces the host's normal foraging and web spinning activity, to produce a special web structure, which are either dense in nature $(N$. bimaculata), or a cupola-like structure ( $T$. varians). These induced that the webbing behaviors were naturally present in the spider itself, but occurred only at the time of specific life history periods, like, before overwintering. Due to the effect of parasite, these modified webbing patterns are obtained in the summer time itself, to protect the wasp pupa (Korenko and Pekár, 2011).

\section{Influencing the host behavior during departure}

So far, we have seen examples on behavior manipulation ofhost by parasites being external to the host. Now, the parasites are internal to the host, entering into the body cavity, feeding on the internal content of the host, and emerging from the body before the changes occur. Cotesia glomerate, a braconid wasp is an endoparasite on different Lepidoperan larvae.

The behavior manipulation was observed when encountered with the wasp. The wasp 
lays eggs inside the body cavity of the host, and the emerging progenies feed on the internal content. At the time of pupation, they exit the host to pupate. At this step, the behavior of the parasitized larva was changed. At the time of parasitoid emergence, the parasitized larva has reduced feeding and the metamorphosis is stopped to make the host remain in the pre-pupal stage (Beckage, 1985). Transient paralysis of the host, makes the pupating wasp to emerge and spin cocoon without interrupting host body movements. Host bleeding was prevented by plugging the emergence hole with their $2^{\text {nd }}$ or $3^{\text {rd }}$ instar sibling (Smith and Smilowitz, 1976). The parasitoid cocoons are now vulnerable to hyperparasitism. So, the host was induced to make vigorous head swings to snap front and back, biting and to secrete fluid droplets, which makes the hyperparasites difficult to attack the wasp cocoon. Besides, the host produces a dense webbing and make a silk mat, that attaches the cocoon strongly with the substrate, and makes the host selection process tedious for the hyperparasites (Brodeur and Vet, 1994). A similar change was observed in Glyptapanteles sp. and its caterpillar host Thyrinteina leucocerae. In the field condition, the parasitized host have shown two fold reduction in the mortality of the wasp cocoons (Maure et al., 2013).

Another example is the manipulation of the ladybird beetle host (Coccinella septumpuncta) by the braconid wasp (Dinocampus coccinellae) while leaving the host, and without the help of sibling wasps, as above (Dheilly et al., 2015). The entomoparsitism of $C$. septumpunctata by the wasp leads to induce protection for the pupating wasp (Triltsch, 1996). The single wasp grub develops inside the host and after 20 days emerge out to pupate.

After the emergence, the host remains alive but paralyzed, twitching its body to protect the pupating wasp from predatory insects. As told before, there is no residing sibling to induce this host, how this manipulation can be occurred? The resulting manipulation was due to the injection of virus Dinocampus coccinellae paralysis virus (DcPV) by the wasp into the host, during oviposition along with the eggs. The presence of virus particles in host, induces an antiviral immune response. Due to the down regulation of multiple genes involved in immune response, the host's nervous tissues allow DcPV neurotropism (ability to invade and live in neural tissue). Later, the accumulation of phagosomes and lysosomes, re-establish the immune system and eliminate the virus from the body, before which the virus gets replicated in host. Then, elimination of high load of virus will lead to neuropathy which triggers the paralysis in the host.

DcPV belongs to Iflavirus group, which was first documented in beneficial insects like silkworm and honeybees. This was highly pathogenic and believed to be the cause for colony collapse disorder in honeybees (van Oers, 2010). This virus is unique, that it mainly replicates in the oviduct of female wasp and produced in abundance to be injected along with the eggs during oviposition into the host (Beckage and Drezen, 2011). Due to these factors, the pathogenic effects are low in wasps. Similarly, the manipulation of lepidopteran larvae by the bauculoviruses causes the affected larva to remain in the exposed foliage of plants when they die ("Wipfelkrankheit"), which enhances the spread of the virions from the dead cadavers (Mehlhorn, 2015). A study has proved that this may be due to the expression of baculovirus gene, ecdysteroid uridine 5'-diphosphate (UDP)glucosyltransferase (egt) encodes the enzyme (EGT), that inactivates the host's moulting hormone 20-hydroxyecdysone (20E), and induced death at the elevated positions (Hoover et al., 2011, Hughes, 2013). 


\section{Ruling the brain by residing in body cavity}

The parasites are capable of controlling the host brain, without direct contact with the brain. Classic examples of this mechanism are the parasitic nematodes and fungus, that have evolved to produce suicidal behavior in the hosts. Adult male and female nematodes are free living in aquatic ecosystem whereas the juvenile forms are parasitic in terrestrial insects which becomes infected through the ingestion of parasitic larva (Schmidt-Rhaesa and Ehrmann, 2001, Hanelt and Janovy Jr, 1999). During the development, the parasitic nematode grows throughout the body cavity and occupies all the body parts except head and legs. Mature nematodes manipulate the behavior of their host by making them search for water and jump into it (Dawkins, 1990, Thomas and Poulin, 1998). The cricket, Nemobius sylvestris was infected by the nematode Paragordius tricuspidatus (Thomas et al., 2002). By distinguishing the host and parasite proteomes during the intimation of water-seeking behavior, it was found that the parasite produces molecules from Wnt family that may act directly on the development of central nervous system (CNS), which causes differential expression of proteins specifically linked to neurogenesis, circadian rhythm and neurotransmitter activities (Biron et al., 2006).

Additional reference was the interaction between the fungus Ophiocordyceps unilateralis and its host worker ant Camponotus leonardi which expressed the death grip behavior soon before death to assist parasite reproduction and spread (Hughes et al., 2011). During foraging, the worker ants were infected by the spores, attach and penetrate the cuticle and progress inside the body (Hughes et al., 2009). The fruiting body, perithecium, was formed as a large stalk from back of the head, from which the spores were spread (Evans and Samson, 1984). For this manipulation, the fungus certainly kills the ant and it is done outside the colony, because ants can eliminate the dead mates out and for the development of perithecia and spore dispersal. The infected ants behaved as zombies, showing random walking patterns and they bite the leaf veins hard by piercing through mandibles. Because of unknown metabolite production or due to the high density of the spores inside the head, the muscles in the mandibles were atrophied and leads to death grips after the death of host (Andersen et al., 2009). Future clarification in this study is awaited.

\section{Relocating to the brain to manipulate behavior}

In the above discussed examples, the jewel wasp envenomated the brain of cockroach by directly injecting ovipositor into the brain or in the case of $D$. coccinellae, the virus (DcPV) was replicated in the brain cells. But in some cases, the parasite present in the haemolymph was carried to the brain through circulatory system (heart), which helps in the migration of the parasite by pumping the insect blood. An example for this type was the behavior manipulation elicited by the liver fluke (trematode) in ants, the second intermediate host, for the completion of its lifecycle. The adult stage of liver fluke (Dicrocoelium dendriticum) occupies the liver of the mammalian host (cattles, humans). After fertilization, the eggs are produced and excreted with the host feces. The eggs were inserted into snails (preceding host), in which the eggs developed into cercariae (freeswimming larval stage). The cercariae were excreted via snail slime, which was fed by ants (intermediate host). Most of the liver fluke cercariae, encysts in the ant haemolymph, while one or two move to ants nervous system, persuading the ants to climb and bite the grass or simply remain motionless (Romig et al., 1980). The former 
manipulation was observed in ants infected by D. dendriticum, while later was observed in D. hospes (Carney, 1969, 1970). In the both cases, the ending was same, the ants climb up to the grass so that they were eaten by the grazing herbivores (Lucius et al., 1980). The biting behavior was induced due to the presence of the parasite in subesophageal ganglia of the head, which controls the cation of mouthparts.

The parasitic organisms have evolved to attack neuroanatomical targets through multiple mechanisms and bring precise behavior manipulation, and paves new window for seeing the functioning of nervous system. To understand the association of the organisms, we should keep a thorough check on natural history and also the biology of the organisms. To discover the underlying mechanisms of the behavior manipulation, an integrated approach of genomics, proteomics and neurophysiology is must. Together with the natural history and integrated approaches, a determined interest will lead to new views in the neuroparsitology of host-parasite interaction. Neurophysiology studies between promising biocontrol agents and herbivorous insect species in future will lead to new breakthrough in IPM practices.

\section{References}

Adamo, Shelley A, and Joanne P Webster. 2013. Neural parasitology: how parasites manipulate host behaviour. The Company of Biologists Ltd.

Akino, T, JJ Knapp, JA Thomas, and GW Elmes. 1999. Chemical mimicry and host specificity in the butterfly Maculinea rebeli, a social parasite of Myrmica ant colonies. Proceedings of the Royal Society of London. Series B: Biological Sciences 266 (1427):14191426.

Andersen, Sandra B, Sylvia Gerritsma,
Kalsum M Yusah, David Mayntz, Nigel L Hywel-Jones, Johan Billen, Jacobus J Boomsma, and David P Hughes. 2009. "The life of a dead ant: the expression of an adaptive extended phenotype." The American Naturalist 174 (3):424433.

Askew, RR. 1971. Parasitic Insects. New York: Amer. Elsevier Publ. Co.

Beckage, Nancy E, and Jean-Michel Drezen. 2011. Parasitoid viruses: symbionts and pathogens: Academic Press.

Beckage, NE. 1985. Endocrine interactions between endoparasitic insects and their hosts. Annual review of entomology 30 (1):371-413.

Biron, DG, Fleur Ponton, L Marché, N Galeotti, L Renault, E Demey- Thomas, J Poncet, SP Brown, P Jouin, and F Thomas. 2006. "'Suicide' of crickets harbouring hairworms: a proteomics investigation." Insect molecular biology 15 (6):731-742.

Brodeur, Jacques, and Jeremy N McNeil. 1989. "Seasonal microhabitat selection by an endoparasitoid through adaptive modification of host behavior." Science 244 (4901):226-228.

Brodeur, Jacques, and Louise EM Vet. 1994. Usurpation of host behaviour by a parasitic wasp. Animal Behaviour 48 (1):187-192.

Carney, W Patrick. 1969. Behavioral and morphological changes in carpenter ants harboring dicrocoeliid metacercariae. The American Midland Naturalist 82 (2):605-611.

Carney, W Patrick. 1970. Brachylecithum mosquensis: infections in vertebrate, molluscan and arthropod hosts. Transactions of the American Microscopical Society: 233-250.

Chapman, RF. 2013. The Insects. Structure and Function. (SJ Simpson and AE Douglas, eds). Cambridge University Press. 
Curtis, Lawrence A. 1987. Vertical distribution of an estuarine snail altered by a parasite. Science 235 (4795):15091511.

Dawkins, Richard. 1982. The extended phenotype. Vol. 8: Oxford University Press Oxford.

Dawkins, Richard. 1990. Parasites, desiderata lists and the paradox of the organism. Parasitology 100 (S1):S63-S73.

Dheilly, Nolwenn M, Fanny Maure, Marc Ravallec, Richard Galinier, Josée Doyon, David Duval, Lucas Leger, Anne-Nathalie Volkoff, Dorothée Missé, and Sabine Nidelet. 2015. "Who is the puppet master? Replication of a parasitic wasp-associated virus correlates with host behaviour manipulation." Proceedings of the Royal Society B: Biological Sciences 282 (1803):20142773.

Eberhard, William G. 2000. "Spider manipulation by a wasp larva." Nature 406 (6793): 255.

Edwards, John P, and Robert J Weaver. 2000. "Endocrine changes in lepidopteran larvae-potential challenges to parasitoid development and survival." Comparative Biochemistry and Physiology--Part B: Biochemistry and Molecular Biology (126):S31.

Evans, HC, and RA Samson. 1984. Cordyceps species and their anamorphs pathogenic on ants (Formicidae) in tropical forest ecosystems II. The Camponotus (Formicinae) complex." Transactions of the British Mycological Society 82 (1):127-150.

Gal, Ram, Maayan Kaiser, Gal Haspel, and Frederic Libersat. 2014. "Sensory arsenal on the stinger of the parasitoid jewel wasp and its possible role in identifying cockroach brains." PloS one 9 (2):e89683.

Galea, Ian, Ingo Bechmann, and V Hugh Perry. 2007. "What is immune privilege (not)?" Trends in immunology 28 (1):12-18.

Godfray, H Charles J, and HCJ Godfray. 1994. Parasitoids: behavioral and evolutionary ecology: Princeton University Press.

Hanelt, Ben, and John J Janovy Jr. 1999. "The life cycle of a horsehair worm, Gordius robustus (Nematomorpha: Gordioidea)."

Hojo, Masaru K, Naomi E Pierce, and Kazuki Tsuji. 2015. "Lycaenid caterpillar secretions manipulate attendant ant behavior." Current Biology 25 (17):2260-2264.

Hoover, Kelli, Michael Grove, Matthew Gardner, David P Hughes, James McNeil, and James Slavicek. 2011. "A gene for an extended phenotype." Science 333 (6048):1401-1401.

Hughes, Austin L. 2013. "Origin of Ecdysosteroid UDPglycosyltransferases of Baculoviruses through horizontal gene transfer from Lepidoptera." Coevolution 1 (1):1-7.

Hughes, David P, Sandra B Andersen, Nigel L Hywel-Jones, Winanda Himaman, Johan Billen, and Jacobus J Boomsma. 2011. "Behavioral mechanisms and morphological symptoms of zombie ants dying from fungal infection." $B M C$ ecology 11 (1):13.

Hughes, David P, Harry C Evans, NIGEL HYWEL- JONES, Jacobus J Boomsma, and Sophie AO Armitage. 2009. "Novel fungal disease in complex leaf- cutting ant societies." Ecological Entomology 34 (2):214-220.

Hughes, David P, and Frederic Libersat. 2018. "Neuroparasitology of parasiteinsect associations." Annual review of entomology 63:471-487.

Kaiser, Maayan, Ryan Arvidson, Raz Zarivach, Michael E Adams, and Frederic Libersat. 2019. "Molecular cross-talk in a unique parasitoid manipulation strategy." Insect 
biochemistry and molecular biology 106:64-78.

Kloss, Thiago Gechel, Marcelo Oliveira Gonzaga, José Augusto Martins Roxinol, and Carlos Frankl Sperber. 2016. "Attack behavior of two wasp species of the Polysphincta genus group (Hymenoptera, Ichneumonidae) on their orb-weaver spider hosts (Araneae, Araneidae)." Journal of Insect Behavior 29 (3):315-324.

Korenko, Stanislav, and Stano Pekár. 2011. "A parasitoid wasp induces overwintering behaviour in its spider host." PloS one 6 (9):e24628.

Lucius, Richard, Thomas Romig, and Werner Frank. 1980.

"Camponotus compressiscapus André (Hymenoptera, Formicidae) an experimental second intermediate host ofDicrocoelium hospes looss, 1907 (Trematodes, Dicrocoeliidae)." Zeitschrift für Parasitenkunde 63 (3):271-275.

Maitland, DP. 1994. "A parasitic fungus infecting yellow dungflies manipulates host perching behaviour." Proceedings of the Royal Society of London. Series B: Biological Sciences 258 (1352):187193.

Maure, Fanny, Simon Payette Daoust, Jacques Brodeur, Guillaume Mitta, and Frédéric Thomas. 2013. "Diversity and evolution of bodyguard manipulation." Journal of Experimental Biology 216 (1):36-42.

Mehlhorn, Heinz. 2015. Host manipulations by parasites and viruses. Vol. 7: Springer.

Moore, Eugene L, Gal Haspel, Frederic Libersat, and Michael E Adams. 2006. "Parasitoid wasp sting: A cocktail of GABA, taurine, and $\beta$ - alanine opens chloride channels for central synaptic block and transient paralysis of a cockroach host." Journal of neurobiology 66 (8):811-820.
Moore, Janice. 2002. Parasites and the behavior of animals: Oxford University Press on Demand.

Piek, T, B Hue, A Lind, P Mantel, and JH Visser. 1989. "The venom of Ampulex compressa--effects on behaviour and synaptic transmission of cockroaches." Comparative biochemistry and physiology. $\quad C, \quad$ Comparative pharmacology and toxicology 92 (2): 175-183.

Pierce, Naomi E, Michael F Braby, Alan Heath, David J Lohman, John Mathew, Douglas B Rand, and Mark A Travassos. 2002. "The ecology and evolution of ant association in the Lycaenidae (Lepidoptera)." Annual review of entomology 47 (1):733-771.

Poulin, R. 1998. "Host specificity; evolutionary ecology of parasitesfrom individuals to communities." Chapman Hall, London:41-69.

Rogers, Matthew E, and Paul A Bates. 2007. "Leishmania manipulation of sand fly feeding behavior results in enhanced transmission." PLoS pathogens 3 (6):e91.

Romig, Thomas, Richard Lucius, and Werner Frank. 1980. "Cerebral larvae in the second intermediate host ofDicrocoelium dendriticum (Rudolphi, 1819) andDicrocoelium hospes looss, 1907 (Trematodes, Dicrocoeliidae)." Zeitschrift für Parasitenkunde 63 (3):277-286.

Schmidt-Rhaesa, Andreas, and Reinhard Ehrmann. 2001. "Horsehair worms (Nematomorpha) as parasites of praying mantids with a discussion of their life cycle." Zoologischer Anzeiger-A Journal of Comparative Zoology 240 (2):167-179.

Smith, CL, and Z Smilowitz. 1976. "Growth and development of Pieris rapae larvae parasitized by Apanteles glomeratus." Entomologia experimentalis et 
applicata 19 (2):189-195.

Thomas, F, and R Poulin. 1998. "Manipulation of a mollusc by a trophically transmitted parasite: convergent evolution or phylogenetic inheritance?" Parasitology 116 (5):431436.

Thomas, F, A Schmidt- Rhaesa, Guilhaume Martin, C Manu, P Durand, and F Renaud. 2002. "Do hairworms (Nematomorpha) manipulate the water seeking behaviour of their terrestrial hosts?" Journal of Evolutionary Biology 15 (3):356-361.

Triltsch, H. 1996. "On the parasitization of the ladybird Coccinella septempunctata L.(Col., Coccinellidae)." Journal of Applied Entomology 120 (1- 5):375378.

van Oers, MM. 2010. "Iflavirus biology and genomics." Insect virology:227-246.

Webster, Joanne P. 2007. "The effect of Toxoplasma gondii on animal behavior: playing cat and mouse." Schizophrenia bulletin 33 (3):752-756.

Weisel-Eichler, Aviva, GAL Haspel, and FREDERIC Libersat. 1999. "Venom of a parasitoid wasp induces prolonged grooming in the cockroach." Journal of Experimental Biology 202 (8):957-964.

\section{How to cite this article:}

Vijayaakshayakumar. N., P. Yasodha and Justin. C. G. L. 2020. Physiology of Neuroparasitism in Insects. Int.J.Curr.Microbiol.App.Sci. 9(07): 861-870.

doi: https://doi.org/10.20546/ijcmas.2020.907.100 